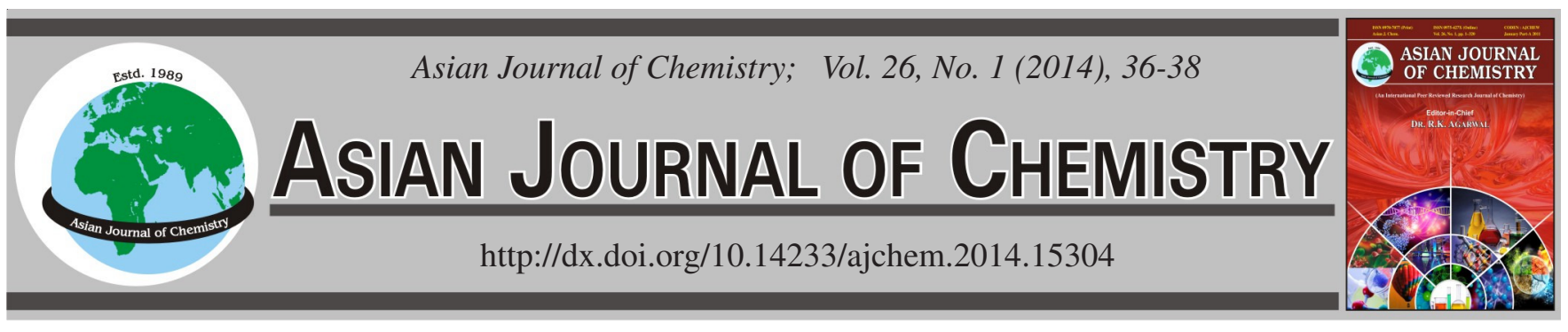

\title{
Isolation and Identification of Insecticidal Component from Roots of Stellera chamaejasme L. Against Locusta migratoria manilensis
}

\author{
Lang Wu ${ }^{1}$, Tao Pü 2 , Manlu GaO ${ }^{2}$, Long $\mathrm{Chen}^{2}, \mathrm{Ke} \mathrm{TaO}^{2}$, Kun LiU ${ }^{2}$ and Taiping $\mathrm{Hou}^{1, *}$
}

${ }^{1}$ Key Laboratory of Bio-Resource and Eco-Environment of Ministry of Education, Sichuan University, Chengdu 610064, Sichuan, P.R. China ${ }^{2}$ College of Life Science, Sichuan University, Chengdu 610064, Sichuan Province, P.R. China

*Corresponding author: Fax: +86 28 85214048; Tel: +86 28 88846045; E-mail: houtplab@scu.edu.cn

Received: 11 February 2013;

Accepted: 12 April 2013;

Published online: 26 December 2013;

AJC-14468

\begin{abstract}
In order to find the effective bio-pesticide to against locusts, we tested the bioactivity of the different extracts from roots of Stellera chamaejasme $L$., respectively. The results of bioassay indicated that petroleum ether extracts had obviously insecticidal activity towards locusts. With silica column chromatography method, we isolated one compound from petroleum ether extracts. Spectra data of ${ }^{1}$ NMR and ${ }^{13} \mathrm{NMR}$ showed the insecticidal compound in the roots of Stellera chamaejasme.L against Locusta migratoria manilensis was dibutyl phthalate. The $\mathrm{LC}_{50}$ of dibutyl phthalate was found to be $292.68 \mathrm{ppm}$.
\end{abstract}

Keywords: Stellera chamaejasme L., Locusta migratoria manilensis, Dibutyl phthalate, Insecticidal activity.

\section{INTRODUCTION}

Stellera chamaejasme L. is a species of Stellera L. There are about 90 species Stellera $L$. and widely distributed in Tibet, Qinghai and Sichuan province of China ${ }^{1}$. Compared with other grassland plants, Stellera chamaejasme L. was viewed as a harmful and destructive plant for its strong viability and fertility. Not only it brought the troubles to the development of animal husbandry, but also threatened the protection of grassland. On the other side, Stellera chamaejasme L. has long been used as the good botanical pesticides by local people. Extracts of Stellera chamaejasme L. have been reported to have a wide spectrum of biological activities including antifungal $^{2}$, antibacterial ${ }^{3}$, antitumor ${ }^{4}$ and insecticidal activity ${ }^{5,6}$, the research of Li Jie found that the petroleum ether extracts of Stellera chamaejasme L. had a strong insecticidal activity against Tetranychus viennensis, the $\mathrm{LC}_{50}$ Was $180 \mathrm{mg} / \mathrm{L}^{7}$. Consequently, Stellera chamaejasmev L. was regarded as new generation insecticide candidates in recent years.

Locust is a kind of worldwide harmful insects. More than 800 species are known in China and about 50 species are harmful to agriculture, forestry and animal husbandry ${ }^{8}$. Every year the locusts causes tremendous losses. Chemical pesticide was efficient to control locust, while it caused a series side effects, such as resistance and environment pollution ${ }^{9}$. It is desirable to find a new class of insecticide which active against locust and friendly to environment.

\section{EXPERIMENTAL}

Root of Stellera chamaejasmev.L was collected from Ruoergai plateau,Sichuan Province of China in 2010. The roots was naturally air dried and grinded with electric mill. All the 3 instars locusts were obtained from Mushan locust farm, Chengdu, Sichuan Province of China and feed on fresh leaves of ryegrass. Gas chromatograph/mass spectrometer (Shimadzu, Japan) was used to qualitative analysis of compound. BrukerAV II -600MHz type nuclear magnetic resonance was used to collect the ${ }^{1} \mathrm{H}$ and ${ }^{13} \mathrm{C}$ NMR spectrum data to identify the compound structure.

Extraction and isolation: The air-dried and ground plant material (100 g)was extracted exhaustively three times with $1 \mathrm{~L}$ of solvent mixture ethanol/water $(95: 5, \mathrm{v} / \mathrm{v})$ for $24 \mathrm{~h}$ at $45^{\circ} \mathrm{C}$. The solvents was evaporated in vacuo to yield the total extracts $(19 \mathrm{~g})$. This extract was then suspended in ethanol and extracted with petroleum ether, methylene chloride, acetic ether and methyl alcohol, respectively. The insecticidal activity of each extracts were applied to the locusts.

The petroleum ether extracts $(1 \mathrm{~g})$ was subjected to silica gel column chromatography(CC) and eluted with a gradient of $n$-hexane and ethyl acetate (10:1,5:1,2:1,1:1,ethyl acetate) to give five fractions (R1-R5). The bioassay showed that fraction of R5 had significant insecticidal activity than others. The fraction R5 (100 mg) was further separated by a silica gel column chromatography with petroleum ether:acetic ether 
$(10: 1,7: 1,5: 1,3: 1$ and ethyl acetate) to obtain three fractions (R51-R53). All fractions were evaluated for insecticidal activity to locust (Table-1). Fraction R52 showed obviously insecticidal activity. The structures of R52 was elucidated by spectroscopic analyses, notably GC-MS and NMR whose structure was presented in Fig. 1.

TABLE-1

INSECTICIDAL ACTIVITY OF FRACTION R51-R53

\begin{tabular}{ccccc}
\hline Fractions & $\begin{array}{c}\text { Time } \\
(\mathrm{h})\end{array}$ & Regression equation & $\begin{array}{c}\text { Value of } \\
\text { regression }\end{array}$ & $\begin{array}{c}\mathrm{LC}_{50} \\
(\mathrm{ppm})\end{array}$ \\
\hline \multirow{2}{*}{$\mathrm{R} 51$} & 120 & $\mathrm{y}=0.484 \mathrm{x}+2.774$ & $\mathrm{R}^{2}=0.92$ & 39126.84 \\
& 144 & $\mathrm{y}=0.452 \mathrm{x}+3.089$ & $\mathrm{R}^{2}=0.86$ & 16705.69 \\
& 168 & $\mathrm{y}=0.655 \mathrm{x}+2.578$ & $\mathrm{R}^{2}=0.86$ & 4952.73 \\
\hline \multirow{3}{*}{$\mathrm{R} 52$} & 120 & $\mathrm{y}=1.512 \mathrm{x}+1.127$ & $\mathrm{R}^{2}=0.98$ & 362.91 \\
& 144 & $\mathrm{y}=1.512 \mathrm{x}+1.666$ & $\mathrm{R}^{2}=0.98$ & 342.01 \\
& 168 & $\mathrm{y}=1.431 \mathrm{x}+1.470$ & $\mathrm{R}^{2}=0.95$ & 292.68 \\
\hline \multirow{2}{*}{$\mathrm{R} 53$} & 120 & $\mathrm{y}=1.261 \mathrm{x}+1.555$ & $\mathrm{R}^{2}=0.99$ & 539.15 \\
& 144 & $\mathrm{y}=1.344 \mathrm{x}+1.413$ & $\mathrm{R}^{2}=0.99$ & 465.13 \\
& 168 & $\mathrm{y}=1.476 \mathrm{x}+1.228$ & $\mathrm{R}^{2}=0.97$ & 357.84 \\
\hline
\end{tabular}

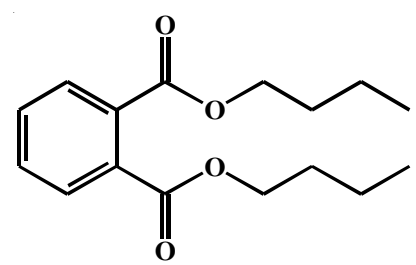

Fig. 1. Structure of compound R52

Compound R52 (17 mg) was obtained as a colourless oil and showed a blue spot under the $254 \mathrm{~nm}$ UV light on TLC. ${ }^{1} \mathrm{H}$ and ${ }^{13} \mathrm{C}$ NMR data of compound R52 was as follows: ${ }^{1} \mathrm{H}$ NMR $\left(600 \mathrm{MHz}, \mathrm{CDCl}_{3}\right) \delta_{\mathrm{H}}: 7.71(2 \mathrm{H}, \mathrm{dd}, J=3.5,5.5 \mathrm{~Hz}$, $\mathrm{H}-3,6), 7.53$ (2H, dd, $J=3.5,5.5 \mathrm{~Hz}, \mathrm{H}-1,2), 4.31$ (4H, t,$J=$ $\left.6.6 \mathrm{~Hz}, \mathrm{H}=8,8^{\prime}\right), 1.72$ (4H, m, $\left.J=6.6 \mathrm{~Hz}, \mathrm{H}=9,9^{\prime}\right), 1.44$ $\left(4 \mathrm{H}, \mathrm{m}, J=7.3 \mathrm{~Hz}, \mathrm{H}=10,10^{\prime}\right), 0.97(6 \mathrm{H}, \mathrm{t}, J=7.3 \mathrm{~Hz}, \mathrm{H}=$ $\left.11,11^{\prime}\right) .{ }^{13} \mathrm{C}$ NMR $\left(600 \mathrm{MHz}, \mathrm{CDCl}_{3}\right) \delta_{\mathrm{C}}: 167.73(\mathrm{C}-7,7)$, 132.33 (C-1,2), 130.92 (C-4,5), 128.85 (C-3,6), 65.58 (C-8, 8'),

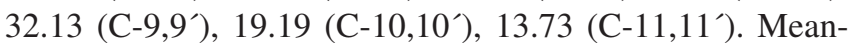
while, the assignment was reconfirmed by HMQC and HMBC experiments.

Insecticidal activity assay: Toxicity of various solvent extracts was screened against 3 instars locusts using WHO method $^{10}$. Five concentrations of the extracts were designed as 20000, 10000, 5000, 2500 and $1250 \mathrm{ppm}$. The sample was dissolved in $1 \mathrm{~mL}$ of acetone and dispersed in 10 Twain water. Thirty locusts ( 3 instars were collected and transferred into the different concentration extracts for $1 \mathrm{~s}$. Control were treated with acetone and 10 Twain water under similar conditions. Each test were replicated three times and kept in a room at $26 \pm 1^{\circ} \mathrm{C}$. Effects of treatments on the mortality were checked each $24 \mathrm{~h}$. Insecticidal activity was calculated by using of Abbott's formula ${ }^{11}$ :

$$
\text { Mortality }(\%)=\frac{\mathrm{N}_{1}}{\mathrm{~N}} \times 100
$$

$\mathrm{N}_{1}$ : the number of death insects, $\mathrm{N}$ : the number of total insects.

$$
\text { Corrected mortality }(\%)=\frac{\mathrm{M}_{1}-\mathrm{M}_{2}}{1-\mathrm{M}_{2}} \times 100
$$

$\mathrm{M}_{1}$ : the rate of mortality in control group, M2: the rate of mortality in treatment group.

The mean mortality data of three replicates per dose were used to calculate the $\mathrm{LC}_{50}{ }^{12}$.

\section{RESULTS AND DISCUSSION}

Preliminary screening showed that the petroleum ether extract was most toxic against locust, followed by methylene chloride, acetic ether and methyl alcohol. The insecticidal activity of the fractions R1-R5 in controlling the locusts were tested at the concentration of $5 \mathrm{mg} / \mathrm{mL}$ (Fig. 2). After $24 \mathrm{~h}$, the corrected mortality of those fractions were not much higher as expected. Nevertheless, with the concentration increased and time extended, there were significant differences in contact toxicity among the five fractions. Fractions R5 and R3 were dramatically increased within $48 \mathrm{~h}$ and the insecticidal activities were 89.65 and $44.82 \%$, respectively. After $96 \mathrm{~h}$, the activity of R5 was $100 \%$. Meanwhile, we can see that the activity of R4 was the weakest fraction which the mean mortality only $13.33 \%$ at $96 \mathrm{~h}$. R5 showed the remarkably toxicity towards locust compared with other fractions from 24 to $96 \mathrm{~h}$. Then R5 was further separated.

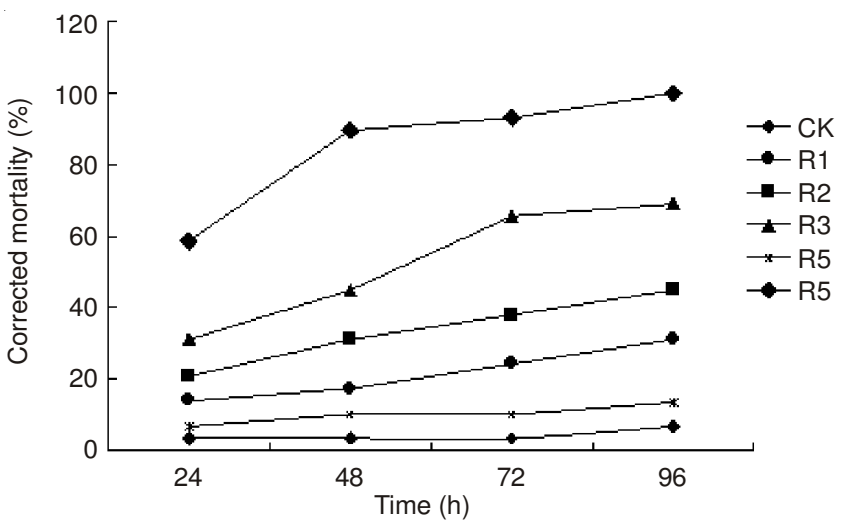

Fig. 2. Insecticidal activity of R-1 to R-5

Insecticidal activity of fraction R51, R52, R53 were noted and presented in Table-1. In our experiments, both R52 and $\mathrm{R} 53$ proved to be active against locust, the $\mathrm{LC}_{50}$ were found to be 292.68 and $357.84 \mathrm{ppm}$, respectively. The proportion of R52 showed a good correlation $\left(\mathrm{R}^{2}=0.95\right)$ with their corresponding $\mathrm{LC}_{50}$. This suggested that $\mathrm{R} 52$ is one parts of the primary active component in roots of Stellera chamaejasmev $L$.

Bioactivity guided fractionation of petroleum ether extract ultimately led to the isolation of R52. Spectral data of R52 were well consistent with the literature ${ }^{13-15}$, the compound was identified as dibutyl phthalate. Dibutyl phthalate is a high production chemical and it have a wide spectrum of industrial and commercial applications, including plasticizers, solvents and in flexible plastics ${ }^{16}$. Xing et al., first isolated dibutyl phthalate from roots of Stellera chamaejasmev $L^{17}$. Bioactivity of dibutyl phthalate has already been observed to be toxic to a variety of aquatic organisms ${ }^{18}$. Antimicrobial efficacy of dibutyl phthalate has also been reported from Streptomyces ${ }^{14,19}$ and it was used as peroxisome proliferator which was an effective compound against demodicidosis ${ }^{20}$, as well as an endocrine disruptor with estrogenic activity ${ }^{21}$. While the insecticidal 
activity of dibutyl phthalate were rarely reported. In this study, we had firstly tested the insecticidal activity of dibutyl phthalate against locust, although the toxicity were not very significant than other reported insecticide, while it would be assistance to investigators to design and preparation of useful and effective insecticide by structural modification. However, there have a lot of works to do, the exact role of dibutyl phthalate in pathogenesis were not well understood and we could not determine whether the observed insecticidal effect resulted from the action of both components of the mixtures or only of dibutyl phthalate. Further research on the application of dibutyl phthalate and the isolation of bioactive constituents from Stellera chamaejasmev L. are undergoing in our laboratory.

\section{Conclusion}

Different polar solvent extracts were evaluated for their insecticidal activities. By the bioactivity assay, it is concluded that the petroleum ether extracts from roots of Stellera chamaejasmev. L has the obviously insecticidal activity against locusts. With the further purification, we discovered that dibutyl phthalate was one of the active ingredients. It was the first time to report that dibutyl phthalate has the insecticidal activity towards locust and also it suggested that the class of phthalate can be used as the insecticide. Meanwhile,R53 also showed a very strong contact toxicity, it is necessary to further separation.

\section{ACKNOWLEDGEMENTS}

This study was financially supported by the National Natural Science Foundation of China (No. 31272068/ C140501) and Hi-tech Research and Development Program of China (863 Program, No. 2011AA10A202-3) and National Key Technology Research and Development Program of the Ministry of Science and Technology of China (2011BAE06B01-23).

\section{REFERENCES}

1. S. Zhicheng, Important poisonous Plants of China Grassland, Chinese Agriculture Publication, China, p. 322 (1997)

2. G. Xiaoxia, L. Wenjuan and O. Yangqiu, J. Sichuan Univ., 43, 687 (2006).

3. L. Wenjuan, G. Xiaoxia and H. Wang, Acta Bot. Boreal.-Occident. Sin., 25, 1661 (2006).

4. F. Weijian, I.K. Tetsuro and Y. Mitsuzi, Chin. J. Cancer Res., 8, 101 (1996).

5. T. Renjun, Z. Li, M. Zhou and Z. Chunguang, J. Sichuan Univ., 42, 1266 (2005).

6. Z. Guozhou, W. Yamei and X. Hanhong, J. Anhui Agric. Univ., 29, 163 (2002).

7. J. Li, F. Zhao and K. Weina, J. Plant Resour. Environ., 16, 31 (2007).

8. G. Shujin, L. Aiping and X. Linbo, Modern AGC, 9, 44 (2010).

9. W. Wenjuan and R. Bingzong, J. Beihua Univ., 6, 481 (2002).

10. World Heath Organization (WHO), Report of the WHO Informal Consultation on the Evaluation on the Testing of Insecticides, Geneva, Switzerland, p. 96 (1996).

11. W.S. Abbott, J. Econ. Entomol., 18, 265 (1925).

12. Z. Zhixiang, X. Hanhong and C. Dongmei, Entomol. Know., 39, 67 (2002).

13. S. Wei, H. Liang, Y.Y. Zhao and Y.Y. Zhang, J. Chin. Mater. Med., 22, 293 (1997)

14. X.-Y. Qu, Q.-Q. Gu, C.-B. Cui, Y.-C. Fang, H.-B. Liu, T.-J. Zhu and W.-M. Zhu, Chin. J. Mar. Drugs, Issue No. 6, 1 (2004).

15. M.E. Savard, J.D. Miller, L.A. Blais, K.A. Seifert and R.A. Samson, Mycopathologia, 127, 19 (1994).

16. O. Bajt, G. Mailhot and M. Bolte, Appl. Catal. B: Environ., 33, 239 (2001).

17. X. Youquan, L. Fengqin and C. Nianhai, J. Heilongjiang Univ., 7, 74 (1990).

18. M. Muneer, J. Theurich and D. Bahnemann, J. Photochem. Photobiol. A: Chem., 143, 213 (2001).

19. M.Y.M. El-Naggar, Biomed. Lett., 55, 125 (1997).

20. F.S Yuan, S.-L. Guo, Z.-X. Qiu, S.-H. Deng and G.-H. Huang, Chin. J. Parasitol. Parasit. Dis., 19, 160 (2001).

21. H. Ohtani, I. Miura and Y. Ichikawa, Environ. Health Perspect., 108, 1189 (2000). 